\title{
Dairy nutrition management: Assessing a comprehensive continuing education program for veterinary practitioners
}

\author{
G. M. Schuenemann, ${ }^{* 1}$ M. L. Eastridge,† W. P. Weiss,† J. D. Workman, ${ }^{\star}$ S. Bas, ${ }^{*}$ and P. Rajala-Schultz \\ *Department of Veterinary Preventive Medicine, and \\ †Department of Animal Sciences, The Ohio State University, Columbus 43210
}

\begin{abstract}
The purpose of this study was to assess the effectiveness of a team-based educational program designed to enhance the flow of applied, research-based, nutrition information to dairy veterinarians. A comprehensive dairy cattle nutrition curriculum was developed and participants from 11 veterinary practices located in 5 states (IN, NY, PA, NM, and $\mathrm{OH}$ ), serving an estimated 186,150 dairy cattle in 469 herds, attended the 2 advanced nutrition modules $(\sim 2.5 \mathrm{~d}$ each and $\sim 40$ $\mathrm{h}$ of learning) held in 2009. Nutrients, feeding transition cows, calves, and heifers, dry matter intake, feed storage, metabolic diseases, evaluating cows (scoring body condition, manure, and lameness), metabolic blood profiles, and feeding behavior were discussed. Educational materials were delivered through in-class lectures, followed by case-based learning and group discussions. A farm visit and out-of-class assignments were also implemented. Attendees were assessed using pre- and post-tests of knowledge to determine the level of knowledge gained in both nutrition modules. Participants evaluated the program and provided feedback at the conclusion of each module. Veterinarians (100\%) reported that the overall program, presentations, and discussions were useful. Attendees found the presented information relevant for their work (agree $=60 \%$ and strongly agree $=40 \%$ ) and of great immediate use to them (neutral $=6.5 \%$, agree $=56 \%$, and strongly agree $=37.5 \%$ ). The presented materials and the implemented educational delivery methods substantially increased the knowledge level of the attendees (16.9\% points increase from pre-test to post-test scores). Importance of feed particle size, ration evaluation, interpreting feed analysis, balancing carbohydrate components, and metabolic profiling in fresh cows were listed as learned concepts that participants could apply in their practices. Results suggested that both nutrition modules were relevant and effective, offering new information with immediate
\end{abstract}

Received October 5, 2010.

Accepted January 12, 2011

${ }^{1}$ Corresponding author: schuenemann.5@osu.edu field application. This program has important implications for dairy veterinarians because they serve as a vital source of information for dairy producers.

Key words: dairy cattle nutrition, veterinary, continuing education

\section{INTRODUCTION}

The average milk yield per dairy cow in the United States has quadrupled over the past 100 yr (VandeHaar and St. Pierre, 2006; NASS, 2010). Advances in genetic selection, nutrition, reproduction, and management have greatly contributed to the increased productivity of dairy cows. Through AI, dairy producers have access to sires that offer high genetic potential for milk yield; however, optimal nutrition is also needed for a cow to phenotypically express the milk yield potential. It is well documented that poor nutrition and management will negatively affect animal health, well-being, and overall herd productivity. According to the National Animal Health Monitoring System (NAHMS) survey, mastitis and reproduction continue as the major health issues for dairy cows, followed by lameness, retained placenta, milk fever, and displaced abomasum (USDA, 2007). Transferring the latest advances in nutritional knowledge to dairy producers will enable them to improve the productivity and profitability of their operations. The veterinary profession has a respected presence in the farm community and is often the primary source of information for dairy producers (USDA, 2008).

Continuing veterinary medical education (CVME) programs provide a unique opportunity for practicing veterinarians to learn about the most recent discoveries in their field and to update their knowledge (Moore et al., 2004; Di Croce et al., 2008; Schuenemann et al., 2010). Comprehensive CVME programs that offer the latest research-based information, encourage discussion between participants and instructors, and promote open communication channels between individuals in the field and the land-grant universities have great likelihood of addressing the ultimate needs of the dairy industry. The purpose of this study was to assess the effectiveness of a team-based educational program de- 
signed to enhance the flow of applied, research-based, nutritional information to dairy veterinarians.

\section{MATERIALS AND METHODS}

\section{Rationale and Background}

Practicing veterinarians must accommodate their busy schedules and update their knowledge and skills on a regular basis to fulfill the demands for continuing education and professional development, and even more importantly, to successfully solve the challenges in the field. Veterinary Extension within the Department of Veterinary Preventive Medicine at The Ohio State University has developed and implemented the Ohio Dairy Health and Management Certificate Program (ODHMCP). The ODHMCP is a comprehensive 3-yr program (approximately $220 \mathrm{~h}$ of in-class training and an additional $40 \mathrm{~h}$ of homework) that consists of eleven 2 to 3 -d modules delivered quarterly (approximately 4 modules per yr). The program was designed for a limited number of attendees $(\mathrm{n}=10$ to 15$)$. The overall goal of this program was to effectively increase veterinary practitioners' knowledge and revitalize their skills in relevant areas of dairy production. Additionally, active communication channels (feedback) have been established to bring the experiences from the field back to the University to help keep the research programs relevant to the needs in the field. Eventually, experiences gained through this program will also enhance the learning opportunities of veterinary students on campus.

\section{Program Description, Educational Content, and Delivery Methods}

As part of the ODHMCP, an advanced dairy nutrition program (2 modules) was developed and implemented in collaboration with the Department of Animal Sciences at The Ohio State University. The cost of the entire ODHMCP ranged from $\$ 5,000$ (if paid up front) to $\$ 6,000$ (if paid in installments) and $\$ 600$ for a single module (Schuenemann et al., 2010). Additionally, participants covered their own transportation and lodging costs. No funding from external sources (e.g., pharmaceutical industry) was received, and the dairy nutrition modules were fully funded by registration fees. With the exception of one participant, all others who attended the first 2 modules on reproductive management (Schuenemann et al., 2010) also attended both nutrition modules, and they continued to be part of the entire ODHMCP. A complete list of modules and educational topics is available at http://vet.osu.edu/ odhmcp.
The dairy nutrition management program was delivered in 2 modules (2.5 d each; in August and December of 2009). Nutrition concepts were presented in a stepwise manner. Nutrients; feeding transition cows, calves, and heifers; DM intake; feed storage; metabolic diseases; evaluating cows (e.g., body condition scoring, manure evaluation, and lameness); metabolic blood profiles; and feeding behavior were discussed (Table 1).

The following learning objectives were developed for the 2 modules on dairy cattle nutrition: (1) to be able to evaluate DMI and factors limiting DMI; (2) to be able to assess dietary fiber, protein, and carbohydrate measures in rations; (3) to be able to evaluate rations for dairy cattle; (4) to be able to assess feeding programs for transition cows and dairy replacements; and (5) to be able to identify sources of supplemental fat, minerals, and vitamins. These learning objectives were designed to help develop the instructional content and assessment instruments (e.g., tests of knowledge; Towns, 2010).

A collaborative learning approach (i.e., in-class lectures, group discussions, case-based learning, demonstrations, and out-of-class assignments) was adopted for the dairy cattle nutrition modules (Smith and MacGregor, 1992; Schuenemann et al., 2010). Educational materials were delivered through in-class lectures (approximately $1 \mathrm{~h}$ in length each; Table 1), followed by case-based learning and group discussions. These learning methodologies were designed to encourage discussion and to emphasize key learning objectives. Two hands-on demonstrations (one for each module) were included as part of the nutrition modules: 1) using a computer program for ration formulation (NRC, 2000) and output interpretation and 2) interpreting feed analyses. These hands-on demonstrations were available to all participants. Participants were asked to bring to the modules a forage analysis, feed samples, and diets for heifers, dry cows, and lactating cows from at least 1 of their clients' dairy herds. Additionally, an out-of-class assignment was given following the first nutrition module (August 2009) to allow participants to transform the information presented into applied skills. Briefly, the assignment was e-mailed to all enrolled participants (an attached PDF file with instructions) 1 mo before the subsequent module (December 2009). Participants were then asked to provide a short oral presentation (approximately $15 \mathrm{~min}$ in length; using Microsoft PowerPoint, Microsoft Corp., Redmond, WA) on dairy nutrition records (i.e., performance of the herd, metabolic diseases, feed costs, feed analyses, water source, quality feeding strategies, and feed storage) using data from one of their clients' herds. The overall goal of the out-of-class assignment was to train participants on the proper analysis and interpretation of dairy nutrition 
Table 1. Description of the nutrition program topics developed for practicing dairy veterinarians

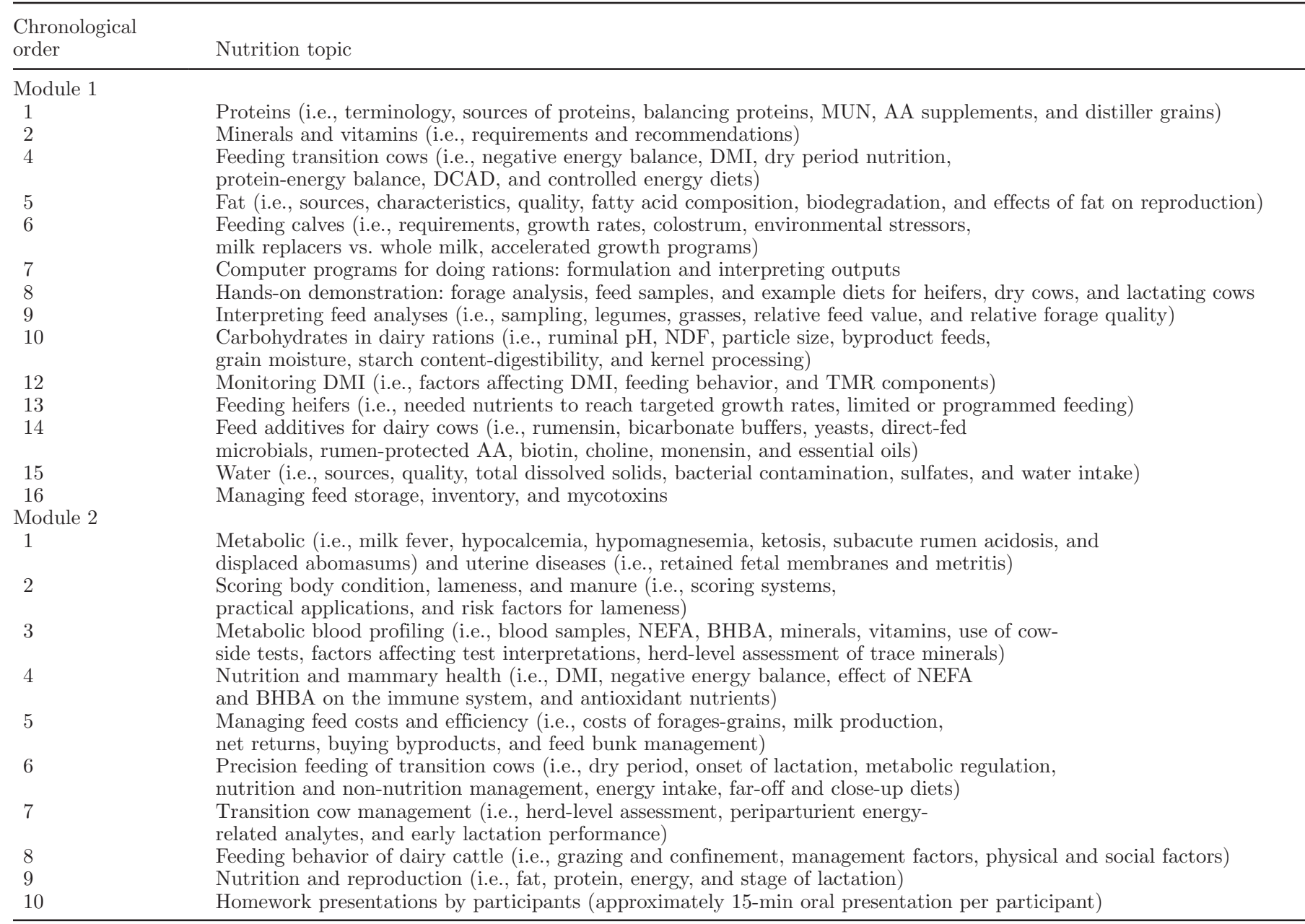

information and engage the group in discussing possible recommendations. The instructors were available to assist and provide feedback to participants before and during the presentations.

At the conclusion of the first module (August 2009), a dairy farm visit was arranged to further strengthen key learning objectives discussed in class. Prior to the farm visit, DHI records for the dairy farm were provided for review by the participants. The dairy farm had approximately 2,000 milking cows housed in freestalls, and heifers were raised by a contract grower. The instructors and participants examined the cows, facilities, and interacted with the owner during the walk-through. Afterward, the instructors and the participants met in a conference room at the farm, without the presence of the owner, to discuss points that related to the topics discussed in the classroom and to assess the strengths and opportunities for the operation. Immediately after the farm visit ( $1 \mathrm{wk}$ ), a letter with recommendations (a summary of inputs from participants and instructors) was provided to the owner and the herd veterinarian. A future module (May of 2011) will address the on-farm communication skills of participants (leadership and personal effectiveness) with the various team members (clients, managers, nutritionists, and employees).

\section{Program Assessment}

For the nutrition modules, pre- and post-tests of knowledge were conducted to measure the level of knowledge gained by participants. At the beginning of each module, participants were asked to answer 10 multiple choice questions related to the topics to be presented during the educational training. The same questions were asked again at the end of the module. This approach allowed us to determine how much knowledge was gained during the modules. Additionally, at the end of both nutrition modules, participants had the opportunity to provide feedback (quantitative and qualitative) and to evaluate the program (e.g., edu- 
Table 2. Estimated distribution of dairy herds (number of herds; \%) based on the number of dairy cows per operation

\begin{tabular}{lcccccc}
\hline & \multicolumn{5}{c}{ Herd size (n of cows) } \\
\cline { 2 - 7 } Item & $\leq 49$ & $50-99$ & $100-199$ & $200-499$ & $500-999$ & $\geq 1,000$ \\
\hline Herds (n; \% in parentheses) & $199(42.4)$ & $71(15.1)$ & $91(19.4)$ & $35(7.5)$ & $23(5)$ & $50(10.6)$ \\
\hline
\end{tabular}

cational materials, contents, and instructors) using a standardized Evaluation of Effective Extension Teaching form (Spiegel, 1992). The evaluation instruments were reviewed by the Office of Responsible Research Practices, The Ohio State University, and determined as exempt from review by the Internal Review Board.

\section{Statistical Analysis}

Reaction data (participants' quantitative feedback) from the evaluation of both nutrition modules (e.g., educational materials, content, and instructors) were reported as frequencies (f) and percentages (\%). Similarly, qualitative feedback (e.g., on program content and benefits to participants) from the evaluation instruments was summarized and reported as text. The percentage of correct answers in each pre- and post-test of knowledge was determined. Because all tests were voluntary and conducted anonymously, it was not possible to identify pre- and post-test scores individually for each participant. Thus, the test scores at the 2 points in time were considered independent and results from the tests conducted before and after the educational modules were compared using t-test comparison method (StataCorp LP, 2009). In addition, A $P$-value $<0.05$ was considered to be statistically significant.

\section{RESULTS}

\section{Assessment of the Nutrition Modules}

The program reached 11 veterinary practices located in 5 different states (IN, NY, PA, NM, and OH). Sixteen veterinarians from these practices, which serve an estimated 186,150 dairy cattle in 469 herds, attended the advanced dairy cattle nutrition modules held in August and December 2009. The distribution of dairy herds by operation size is shown in Table 2 .

\section{Tests of Knowledge and Satisfaction with the Program}

The pre- and post-tests of knowledge were voluntary and conducted anonymously, using 10 questions per module (Table 3). The number of total tests of knowledge differed for module 1 (15 pre- and 11 post-tests) and module 2 (10 pre- and 9 post-tests). According to the pre- and post-tests of knowledge, the educational materials and the implemented delivery methods substantially increased the knowledge level of the attendees $(16.9 \%$ points increase from pre-test to post-test scores; Table 4). Veterinary participants agreed that the overall information provided was appropriate and relevant, and they indicated that the presentations and discussions were both useful and applicable (Table 5). Additionally, participants valued the information presented on metabolic blood profiling, as well as the farm visit followed by group discussions (Table 5). The casebased learning and homework assignments were ranked as useful learning methods by participants (Table 5).

\section{Assessment of Educational Content, Farm Visit, and Instructors}

At the conclusion of the nutrition modules, participants assessed the educational materials presented and preparedness of the instructors. Participants indicated that the information presented was relevant for their work with immediate field application (Table 6). The overall goal was to evaluate the effectiveness of the program in addressing current nutrition issues encountered in the field by the attending veterinarians. Results from this evaluation suggested, according to participants, that the instructors were well prepared, organized, and delivered a clear message to attending veterinarians. Although the most relevant dairy nutrition management topics were discussed, no information was presented on nutrition strategies for organic dairy farms. Additionally, participants were asked to list something (e.g., practices or skills) they learned during the educational program that could be applied in their practices. Several learned skills or practices were listed by participants immediately after each educational module, such as importance of feed particle size, ration evaluation, interpreting feed analysis, carbohydrate components, and metabolic profiling in fresh cows. The qualitative feedback from enrolled participants was an important component of the overall program evaluation. Most of the qualitative statements collected referred to the attendee's satisfaction with the program, the value of speaker presentations or discussions, and the educational material provided (such as case-based studies and handouts). 
Table 3. Tests of knowledge used to assess the level of knowledge gained by participants in both nutrition modules ${ }^{1,2}$

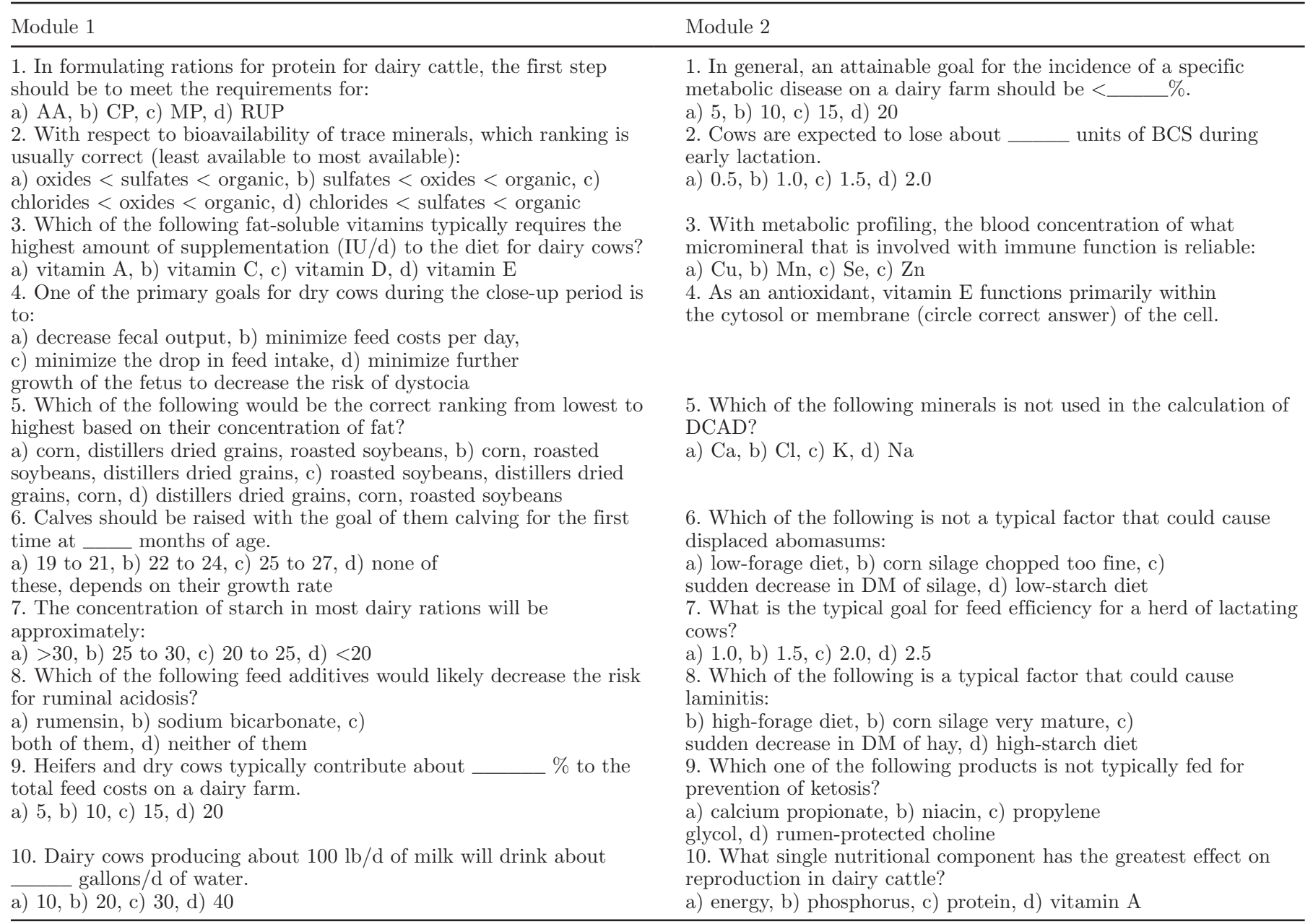

${ }^{1}$ The anonymous tests of knowledge were provided to participants immediately before and after the delivery of each nutrition module to assess the level of knowledge gained by participants.

${ }^{2}$ The following are the correct answers for the tests of knowledge: Module 1: 1) c, 2) a, 3) a, 4) c, 5) a, 6) b, 7) b, 8) c, 9) c, and 10) d; Module 2: 1) a, 2) b, 3) c, 4) membrane, 5) a, 6) d, 7) b, 8) d, 9) c, and 10) a.

Based on the visit and discussions at the dairy farm, a recommendation letter was prepared by the instructors and it was shared with the owner, farm nutritionist, and course participants. The following suggestions were presented to the owner: (1) deeper commodity bays to decrease feed shrinkage and improve feed quality; (2) improve face management of corn silage bunk to improve feed quality; (3) due to having a 6-row barn and overstocking, feed bunk space was limited so increased feeding frequency was advised; (3) suggested initiating more groups, especially the formation of a first-lactation group; (4) formulation of a lower-cost, lower energy-dense ration for late lactation cows; and (5) a notable drop in milk fat percentage was occurring (based on the first DHIA test) from 41 to 100 DIM, possibly attributed to TMR particle size from excessive mixing time observed during the visit.

\section{DISCUSSION}

The assessment of the 2 nutrition modules provided evidence that (1) the information delivered during the modules significantly increased the knowledge level of participants, and (2) both nutrition modules were relevant and effective, offering new information with immediate field application.

Assessing learning needs is an important component in any CVME program, not only for program accreditation, but also for post-delivery assessments and curriculum development (Moore et al., 2004). A comprehensive CVME program must be able to (1) provide new knowledge for immediate field application, (2) encourage discussion, (3) collect feedback, and (4) follow-up after program delivery (with participants and instructors). In addition to the topic(s) to be presented, 
Table 4. Percent correct responses to pre- and post-test questions from a continuing education program in dairy cattle nutrition for practicing dairy veterinarians

\begin{tabular}{lccc}
\hline Question & $\begin{array}{c}\text { Pre-test } \\
\text { (\% correct) }\end{array}$ & $\begin{array}{c}\text { Post-test } \\
\text { (\% correct) }\end{array}$ & $P$-value \\
\hline Module $1^{1}$ & & & \\
1 & 53.3 & 100.0 & 0.006 \\
2 & 26.6 & 81.8 & 0.004 \\
3 & 26.6 & 81.8 & 0.82 \\
4 & 93.3 & 91.0 & 0.87 \\
5 & 66.6 & 63.6 & 0.22 \\
6 & 86.6 & 100 & 0.25 \\
7 & 60.0 & 81.8 & 0.54 \\
8 & 66.6 & 54.5 & 0.62 \\
9 & 26.6 & 18.2 & 0.19 \\
10 & 46.6 & 72.7 & 0.001 \\
Overall & 55.3 & 75.0 & 0.34 \\
Module $2^{2}$ & & & 0.85 \\
1 & 70.0 & 88.9 & 0.03 \\
2 & 60.0 & 55.5 & 0.53 \\
3 & 60.0 & 100.0 & 0.10 \\
4 & 80.0 & 66.7 & - \\
5 & 40.0 & 77.8 & 0.08 \\
6 & 100.0 & 100.0 & 0.53 \\
7 & 70.0 & 100.0 & 0.27 \\
8 & 80.0 & 66.7 & 0.61 \\
9 & 20.0 & 44.4 & 0.04 \\
Overall & 80.0 & 88.9 & 0.001 \\
Modules 1 and 2 combined $^{3}$ & 66.0 & 78.9 & \\
20 & & & \\
\hline
\end{tabular}

${ }^{1}$ Percent correct answers were calculated from 15 pre- and 11 post-tests.

${ }^{2}$ Percent correct answers were calculated from 11 pre- and 9 post-tests.

${ }^{3}$ Percent correct answers were calculated taking into account the total number of tests of knowledge obtained per module using a weighted average.

course coordinators must provide timely suggestions to the instructors (i.e., learning objectives, expectations, and needs of the group) before delivery of the information to increase the likelihood of conveying a clear message to attendees. Although veterinarians enrolled in both nutrition modules shared common dairy nutrition management challenges and needs, practicing veterinarians from the northeast region worked mostly with small dairy operations (fewer than 100 cows), as opposed to those from the southwest region who worked mostly with large dairy herds $(\geq 1,000$ cows).

Instructors delivered the information through inclass lectures, case-based learning, group discussions, homework assignment, and a farm visit. Recognizing and integrating experiences from veterinarians into educational programming may help motivate veterinary practitioners to adopt the latest nutritional advances; ultimately enhancing dairy sustainability (Nordström

Table 5. Summary of responses (frequency; percentages in parentheses) regarding the satisfaction of participants with the overall nutrition program

\begin{tabular}{|c|c|c|c|c|c|}
\hline $\begin{array}{l}\text { Program evaluation } \\
\text { and input item }\end{array}$ & Useless & $\begin{array}{l}\text { Somewhat } \\
\text { useful }\end{array}$ & Useful & $\begin{array}{l}\text { Quite } \\
\text { useful }\end{array}$ & $\begin{array}{l}\text { Very } \\
\text { useful }\end{array}$ \\
\hline How do you rate the overall program? & $0(0)$ & $0(0)$ & $4(19.0)$ & $9(42.9)$ & $8(38.1)$ \\
\hline $\begin{array}{l}\text { Please rate the importance of the speaker presentations } \\
\text { and discussions }\end{array}$ & $0(0)$ & $0(0)$ & $0(0)$ & $11(52.4)$ & $10(47.6)$ \\
\hline Please rate the farm visit and group discussions & $0(0)$ & $0(0)$ & $5(38.5)$ & $4(30.8)$ & $4(30.8)$ \\
\hline $\begin{array}{l}\text { How would you rate the information presented } \\
\text { on metabolic blood profiling? }\end{array}$ & $0(0)$ & $0(0)$ & $3(23.0)$ & $5(38.5)$ & $5(38.5)$ \\
\hline How would you rate the homework assignment and discussions? & $0(0)$ & $0(0)$ & $2(28.6)$ & $3(42.9)$ & $2(28.6)$ \\
\hline
\end{tabular}

${ }^{1}$ This voluntary evaluation instrument was provided to participants to assess the satisfaction of participants with the overall nutrition program at the conclusion of each educational module. 
Table 6. Summary of frequency and percentages (in parentheses) of the total responses per statement on the educational materials, content, and instructors of the nutrition program ${ }^{1,2}$

\begin{tabular}{|c|c|c|c|c|c|}
\hline $\begin{array}{l}\text { Program evaluation } \\
\text { and input statement }\end{array}$ & $\begin{array}{l}\text { Strongly } \\
\text { disagree }\end{array}$ & Disagree & $\begin{array}{c}\text { Neither } \\
\text { disagree } \\
\text { nor agree }\end{array}$ & Agree & $\begin{array}{l}\text { Strongly } \\
\text { agree }\end{array}$ \\
\hline 2. Provided information relevant to my work & $0(0)$ & $0(0)$ & $0(0)$ & $161(60.0)$ & $107(40.0)$ \\
\hline 3. Were based on current, up-to-date information & $0(0)$ & $0(0)$ & $9(3.3)$ & $81(30.1)$ & $179(66.5)$ \\
\hline 4. Addressed the topic identified in the title of the program & $0(0)$ & $0(0)$ & $6(2.2)$ & $80(29.9)$ & $182(67.9)$ \\
\hline 7. Will be of great immediate use to me & $0(0)$ & $0(0)$ & $17(6.4)$ & $150(56.2)$ & $100(37.4)$ \\
\hline
\end{tabular}

${ }^{1}$ This voluntary evaluation instrument was provided to participants to assess the effectiveness of the program and benefit to participants at the conclusion of each educational module. The evaluation instrument was adapted from the Evaluation of Effective Extension Teaching instrument (form II), The Ohio State University Extension (Spiegel, 1992).

${ }^{2}$ Each speaker for each topic was evaluated, resulting in a high number of responses per question.

Källström and Ljung, 2005). In CVME, 4 levels of summative evaluation have been reported (Andreasen et al., 2001; Moore et al., 2004). This study assessed participant perceptions about the program (level 1) and competence with new knowledge or skills (level 2). Adopting the new practices learned (behavioral change; level 3) and the on-farm effect (level 4) will require further investigation. Although some participants correctly answered the pre-tests, the overall result of the post-tests indicated that participants acquired new nutritional-related knowledge. The proportion of correct responses significantly increased $(P<0.01)$ for 3 of 10 questions in module 1 and tended to increase $(P<$ $0.10)$ for 3 of 10 questions in module 2. The knowledge about feed costs appeared to be low (module 1; question 2), but financial management of dairy farms was presented and discussed in a later module. Although knowledge about products for prevention of ketosis (module 2; question 9) is expected to be high among veterinarians, the clarity of the question relative to feeding versus drenching was likely inadequate. Overall, attendees found the information relevant for their work and of great immediate use to them. Information specifically intended for organic dairy systems (e.g., grazing strategies with supplementations, and allowed additives, vitamins, and minerals), an area that will be addressed in future programming, was not provided in these 2 nutrition modules. However, this information would have definitely benefited several enrolled participants who are currently working with organic dairy farms.

Assessing knowledge gained by participants in CVME programs is important as a precursor to achieve behavioral change (Bennett, 1975). The questions in the tests of knowledge were developed to assess the program learning objectives through cognitive recall data or information (multiple choice and completion items; Bloom et al., 1956; Jacobs, 2004). No single evaluation method is sufficient to assess the knowledge gained (Ho et al., 2003). In this program, we tried to minimize guessing (completion items), as well as to provide a wide sampling of contents for each objective (multiple-choice items) during the short evaluation period (15 min in length for the pre- and post-tests). The taxonomy of learning presented by Bloom et al. (1956) provides useful information on writing educational objectives, designing instructions, and assessing educational learning. In this program, current evaluation efforts have been focused on both satisfaction of participants and knowledge change. It is important that participants are very satisfied with the content and learning achieved from the educational programming. Also, it is important that they understand and demonstrate a mastery of new knowledge. In practice, research-based knowledge must be applied on the farm and actually be used to have a substantial effect on the farm or on the dairy industry. This higher-level evaluation requires the collection of evidence (change in herd performance) to measure program success long after programming has ended. Usually, people need sufficient time to practice and apply the information to their individual situations or systems. This program was designed to build confidence (through group discussions, oral presentations, farm visits, and case studies) of the learned skills by participants. In future programming, efforts will focus on additional development of comprehensive case studies, followed by group discussions, hands-on demonstrations, and pre-arranged follow-up visits with participants. This will allow for the assessment of behavioral changes by participants and the on-farm effect.

The overall objective of this comprehensive nutritional program was to increase the ability of dairy veterinarians to identify and solve nutritionally related 
issues on dairy farms, especially to decrease the incidence of nutritionally related diseases. According to the NAHMS survey, dairy veterinarians are typically not the primary people responsible for balancing feed rations (USDA, 2007). However, nutrition is a key component of herd health and productivity. Unlike other experts in dairy farming, veterinarians regularly visit their clients and are ideally placed to identify at-risk dairy herds likely to benefit from nutritional knowledge. Nutrition affects prevalence of many diseases, including mastitis and reproductive disorders (Goff, 2006). According to the NAHMS survey, mastitis and reproduction remain as the major health issues for dairy cows, followed by lameness, retained placenta, milk fever, and displaced abomasum (USDA, 2007). Malnutrition of the periparturient cow (negative calcium or energy balance) clearly increases the susceptibility of common metabolic (milk fever and ketosis) and infectious disorders, such as uterine diseases (i.e., retained fetal membranes; Goff, 2006). During the transition period, periparturient cows have decreased DMI (thus, nutrient intake) a few days before and after calving. Proper nutrition and management of the transition cow period is key to maintaining healthy cows capable of reproducing, free of infectious or metabolic diseases, and able to produce profitable amounts of milk. Nutritional concepts on DMI, nutrients (fat sources, minerals, vitamins, proteins, and carbohydrates), and assessment of feeding programs for transition cows (blood profiling) and dairy replacements were presented and discussed extensively (hands-on exercises and farm visit) during the nutrition program. Furthermore, participants were asked to complete a homework assignment (information on herd performance, nutrition, feed costs-efficiency, and metabolic disorders) to apply the concepts learned in class into practical applications using one of their clients' herds. Additionally, as part of the homework assignment, attending veterinarians were asked to provide a short oral presentation (approximately $15 \mathrm{~min}$ ) on the assignment to engage other participants in discussing the information provided and to provide alternative suggestions for improvement. This learning-by-doing methodology allowed participants not only to apply the learned concepts to real-world problems, but also to receive constructive feedback from the instructors. This learning exercise is paramount to build confidence and to increase the likelihood of adopting the latest nutritional practices by participants (Chase et al., 2006). Veterinarians have shown strong support for this type of learning methodology in the past (Schuenemann et al., 2010) and in this program.

Although the adoption of newly learned practices or skills is the ultimate goal for continuing education pro- viders, satisfaction with the course does not necessarily indicate behavior change (Moore et al., 2004). Collecting qualitative feedback from participants is important to assess the performance of the program. Qualitative feedback best describes how fully engaged participants were during the learning process and their level of satisfaction with the educational program (Diem, 2002). Qualitative comments were positive about the overall program, course materials, educational content (intensity of presentations and volume of information presented), and the instructors. Both qualitative and quantitative feedback from participants provided evidence that nutritional information with immediate field application was delivered. Further investigation is needed to determine whether these applied nutritional concepts will translate into behavioral changes (e.g., adoption of learned practices or skills) and result in on-farm effect. A complete evaluation of the real onfarm effect (through behavior change of applying new practices or skills by participants) resulting from the program will require additional study. This additional program evaluation will help us to determine the long-term effectiveness of the program in transferring new knowledge or skills through the learning methods implemented.

In conclusion, the assessment of the participant feedback and the tests of knowledge provided evidence that both nutrition modules were relevant and offered information with immediate field application. The program substantially improved veterinarians' knowledge on dairy nutrition and management. Findings from this study, including the qualitative feedback, provide critical information for planning future courses. For the program to be considered entirely successful, a detailed follow-up assessment on the adoption of learned practices or skills (e.g., behavior change) by participants and their on-farm effect would be needed. This program serves as an effective model for others desiring to organize and implement a comprehensive continuing education program for veterinarians.

\section{ACKNOWLEDGMENTS}

The authors thank the speakers: T. Overton (Department of Animal Science, Cornell University, Ithaca, NY), N. Botheras (Department of Animal Science, The Ohio State University, Columbus), T. Herdt (Department of Large Animal Clinical Sciences, Michigan State University, East Lansing), J. Drackley (Department of Animal Sciences, University of Illinois, Urbana-Champaign), and R. Shaver (Department of Dairy Science, University of Wisconsin, Madison) for their valuable contributions, as well as the practicing veterinarians 
who participated in the dairy nutrition management modules of the Ohio Dairy Health and Management Certificate Program.

\section{REFERENCES}

Andreasen, L., J. L. Beert, and M. Stone. 2001. Outcomes measurement: Are you ready? Almanac 23:8-9. Newsletter of the Alliance for Continuing Medical Education.

Bennett, C. 1975. Up the hierarchy. J. Ext. 13:7-12.

Bloom, B., M. Englehart, E. Furst, W. Hill, and D. Krathwohl. 1956. Taxonomy of educational objectives: The classification of educational goals. Handbook I: Cognitive Domain. Longmans, Green \& Co., New York, NY, Toronto, ON, Canada.

Chase, L. E., L. O. Ely, and M. F. Hutjens. 2006. Major advances in extension education programs in dairy production. J. Dairy Sci. 89:1147-1154

Di Croce, F. A., P. H. Bergonzelli, A. L. Soraci, and G. M. Schuenemann. 2008. Evaluation of a continuing education program for veterinarians: Outcome assessment of applied reproductive techniques in beef production. Reprod. Fertil. Dev. 20:86.

Diem, K. G. 2002. Using research methods to evaluate your extension program. J. Ext. 40:FEA1. Accessed September 14, 2010. http:// www.joe.org/joe/2002december/a1.php.

Goff, J. P. 2006. Major advances in our understanding of nutritional influences on bovine health. J. Dairy Sci. 89:1292-1301.

Ho, K., A. Chockalingam, A. Best, and W. Geoff. 2003. Technologyenabled knowledge translation: Building a framework for collaboration. CMAJ 168:710-711.

Jacobs, L. C. 2004. How to write better tests: A handbook for improving test construction skills. IUB Evaluation Services and Testing. Accessed November 11, 2010. http://www.indiana.edu/ best/ write_better_tests.shtml.

Moore, D. A., R. O. Gilbert, W. Thatcher, J. E. Santos, and M. W Overton. 2004. Levels of continuing veterinary medical education program evaluation: Assessing a course on dairy reproductive management. J. Vet. Med. Educ. 31:146-155.
NASS. 2010. Data and statistics. United States Department of Agriculture, National Agricultural Statistics Service. Accessed September 14, 2010. http://www.nass.usda.gov/Data_and_Statistics/ Quick_Stats/.

Nordström Källström, H., and M. Ljung. 2005. Social sustainability and collaborative learning. Ambio 34:376-382.

NRC. 2000. Nutrient Requirements of Dairy Cattle. 7th rev. ed. Version 1.0 .

Schuenemann, G. M., S. Bas, J. D. Workman, and P. Rajala-Schultz. 2010. Dairy reproductive management: Assessing a comprehensive continuing education program for veterinary practitioners. J. Vet. Med. Educ. 37:289-298.

Smith, B. L., and J. T. MacGregor. 1992. What is collaborative learning? Pages 10-29 in Collaborative Learning: A Sourcebook for Higher Education. A. S. Goodsell, M. R. Maher, V. Tinto, B. L. Smith, and J. MacGregor, ed. National Center on Postsecondary Teaching, Learning, and Assessment at Pennsylvania State University, University Park.

Spiegel, M. 1992. Synthesizing evaluation: Perspectives, practices and evidence. Pages 27-37 in Proceedings of the American Evaluation Association 92: Extension Evaluation Education Topical Interest Group, Seattle, WA. American Evaluation Association, Fairhaven, MA.

StataCorp LP. 2009. Stata Statistical Software. Release 11. College Station, TX.

Towns, M. H. 2010. Developing learning objectives and assessment plans at a variety of institutions: Examples and case studies. J. Chem. Educ. 87:91-96.

USDA. 2007. Dairy 2007, Part I: Reference of dairy cattle health and management practices in the United States. Accessed September 14, 2010. http://www.aphis.usda.gov/vs/ceah/ncahs/nahms/ dairy/.

USDA. 2008. Dairy 2007, Part III: Reference of dairy cattle health and management practices in the United States. Accessed September 14, 2010. http://www.aphis.usda.gov/vs/ceah/ncahs/nahms/ dairy/.

VandeHaar, M. J., and N. St-Pierre. 2006. Major advances in nutrition: Relevance to the sustainability of the dairy industry. J. Dairy Sci. 89:1280-1291. 